\title{
Work-related musculoskeletal disorder and its costs: a short review
}

\author{
Ana Sophia Rosado ${ }^{1}$, J. Santos Baptista² and J. C. Guedes ${ }^{3}$
}

\begin{abstract}
Faculty of Engineering, University of Porto, PT (anasgmr@yahoo.com.br) ORCID 0000-0002-4935-4171, ${ }^{2}$ Associated Laboratory for Energy, Transports, and Aeronautics - LAETA (PROA), Faculty of Engineering, University of Porto, PT (jsbap@fe.up.pt) ORCID 0000-0002-8524-5503, ${ }^{3}$ Associated Laboratory for Energy, Transports, and Aeronautics - LAETA (PROA), Faculty of Engineering, University of Porto, PT (jccg@fe.up.pt) ORCID 0000-0003-2367-2187.
\end{abstract}

https://doi.org/10.24840/978-972-752-279-8 0056-0064

\begin{abstract}
Introduction: Musculoskeletal disorder can result from extreme physical demands at work. It has risen, mainly due to high muscle demands and static postures and generates a significant economic burden to the companies. This short review aims to point out the statistics of the most affected body parts by workrelated musculoskeletal disorders, assess absenteeism and presenteeism costs, and evaluate the effectiveness of the interventions. Methodology: According to the PRISMA Statement, the search was performed in 5 electronic databases (Scopus, Web of Science, Science Direct, Pubmed). Articles selection was made by the title and abstract analysis, especially those aiming to explain and validate the subject. If the abstract fulfils the objective, the articles were read, and studies were considered that met the defined eligibility criteria. Were chosen articles that realised measurements or considered interventions in healthy human beings, especially in the working population, dated from 2015 to 2020. Results and Discussion: The scrutinised articles were conclusive that the most affected part of the body are the upper limbs, the neck and the upper back. The statistics of the affected workers varied according to the country and analysed tasks, but they converge concerning the most affected body parts. It could be noted that women are more affected by musculoskeletal disorders than men, especially older women; the reason, however, is not clearly explained. Muscle injury can lead high economic burden, mostly due to absenteeism and presenteeism. It was noted that the expenditure due to presenteeism is higher comparing to absenteeism in both developed and emergent countries. Conclusions: Due to high costs, companies are deploying strategies to improve work conditions and aware the workers about health and safety. Interventions have shown to be effective in reducing the risk of injuries. Work-related musculoskeletal disorders can be extremely damaging to the workers' health and are costly to the companies. Support supervisor interventions effectively improve work conditions and reduce the risk of damaging outcomes, increasing workers' health, work ability, and, consequently, productivity.
\end{abstract}

Keywords: Injury, Absenteeism, Presenteeism, Strategies.

\section{INTRODUCTION}

The high physical load and repetitive movements are the leading causes of musculoskeletal disorders associated with emotional stress (Atroszko et al., 2020). Physical exhaustion results in muscular frailty and can be aggravated by awkward postures, repetitive tasks, and static position, which propitiate the risk of injury (Hembecker et al., 2017) (Knoop et al., 2019).

Work-related musculoskeletal disorders (WMSD) are a reality in companies worldwide and represent the highest disease rate (Acaröz et al., 2019). It is a crucial factor to be assessed since it directly relates to the employees' health, safety, and productivity (Caldwell et al., 2019).

Illnesses originated from overwork precedes high economic burden to workers companies, especially due to presenteeism and absenteeism (Silva et al., 2018). Musculoskeletal disorder is the leading cause of work absenteeism in Europe, affecting over 40 million workers. It leads to disability around the globe in $20 \%-33 \%$ and represents up to $40 \%$ of occupational costs (Moussavi, Zare, Mahdjoub, \& Grunder, 2019) (Santos \& Mendes, 2020) (Crawford et al., 2020). The World Health Organization (WHO) recognises that an unsuitable working environment precedes physical and mental health problems, raising the risk of sick leave and loss of productivity (Atroszko et al., 2020).

Considering the high associated costs, companies are becoming aware of improving working conditions, as well as reducing productivity losses and sick leave (Jonge et al., 2019) (Atroszko et al., 2020).

Although various factors contribute to the loss of work capacity, WMSD has proved to be one of the most important. This study is a short review to point out the most affected body parts and 
evaluate absenteeism and presenteeism as harm outcomes resulting from musculoskeletal disorders.

\section{METHODOLOGY}

The review was done by the analysis of articles, which could be reviews and individual researches. The analysis of each article was verified, on the first moment, the title and the abstract. If the abstract fulfils the goal, then the lecture of the full articles was performed. The selection reflected only articles that considered healthy human beings and workers of working age. Articles evaluating outdoor work and measurement methods utilising Rula, Reba, Ocra, Owas, and NIOSH were not considered.

The databases used were: Scopus, Web of Science, Science Direct, Pubmed. The words used in the investigation were:

- cost absenteeism AND employers;

- increase health AND absenteeism;

- loss productivity AND injury;

- musculoskeletal AND absenteeism AND presenteeism AND cost;

- musculoskeletal AND body region;

- musculoskeletal disease AND body part;

- musculoskeletal disorder AND reduce productivity;

- work capacity AND tiredness;

- work capacity AND increase AND health;

- work capacity evaluation AND tiredness;

- work productivity AND absenteeism AND presenteeism.

This systematic review was performed according to the PRISMA Statement (Moher D. et al., 2009), and the research was updated to March 2021. The investigation of the articles resulted in: summary of the collected articles with 33209 articles pre-selected. Applying the exclusion criteria, 24648 papers were excluded by "date" (articles published in the period between 2015 and 2020 were included); 3446 were rejected by "document type" (only articles and review articles were accepted); 11 texts were refused due to "language" (only English was accepted). After articles exclusion according to the explained criteria, were read the titles and abstracts of the remaining ones. 5073 articles were excluded because they are not consistent with the goal of this Short review. Finally, 31 articles were used for analysis in this work. Of all analysed articles, thirteen exhibited the statistics of the most injured part of the body by WMSD, five articles compared the costs of absenteeism and presenteeism due to musculoskeletal disorder, and the other investigated articles justified this systematic review.

Articles before 2015 were considered due to their importance about the topic.

\section{RESULTS AND DISCUSSION}

Most common sites pain

Work-related musculoskeletal disorders can affect workers and companies of different sectors. The consequences can be damaging to the health of the workers and the economy of companies (Acaröz et al., 2019). Due to its severity, several kinds of research have been made to understand the most affected gender, regions of the body, and costs.

It was noted that women are more susceptible to WMSD, and it is twice as common in older women than in man (Pensola et al., 2016; Knoop et al., 2019; Acaröz et al., 2019; Troelstra et al., 2020). However, no author has explained clearly the reason why women are most affected. 
Several researchers have scrutinised the part of the body with the highest rate of WMSD. Figure 1 shows the result of thirteen articles (number $1-13$ on the $X$-axis). It is known that musculoskeletal injuries disturb workers from different sectors. Tasks with physical demands and intellectual workers are both touched by bodily injuries. Figure 2 illustrates the result of thirteen analysed articles (numbers 1-13 on the X-axis), concerning the most affected body parts, considering different jobs, such as health workers (nurses, physicians, physical therapists), financial services workers, manufacturing workers, academicians, supermarket cashiers, construction workers.

It must be highlighted that the used methods for the evaluation mainly were the Nordic Musculoskeletal Questionnaire, but also were used the Dutch Musculoskeletal Questionnaire, Work Ability Index, Institute for Medical Technology Assessment Productivity Cost Questionnaire (iPCQ), Work Productivity and Activity Impairment Questionnaire, and health examination. In addition, musculoskeletal pain and disorder from the past twelve months were considered.

Figure 1, illustrates the most affected parts of the body due to WMSD, in indoor activities.

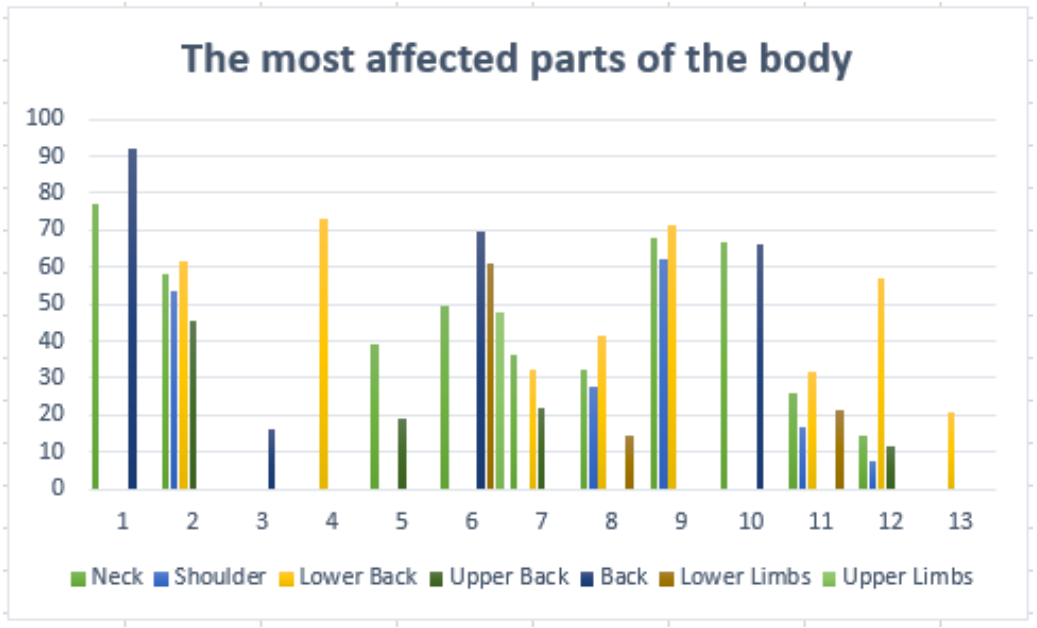

Figure 1. The parts of the body most affected by WMSD.

The evaluation of the articles permits to conclude that the incidence of WMSD is mainly in the neck and back. Figure 2 illustrates the statistics of the three most affected body parts.

It must be underlined that the back pain can be related to the upper back or lower back. Some of the articles did not explain the exact location. 


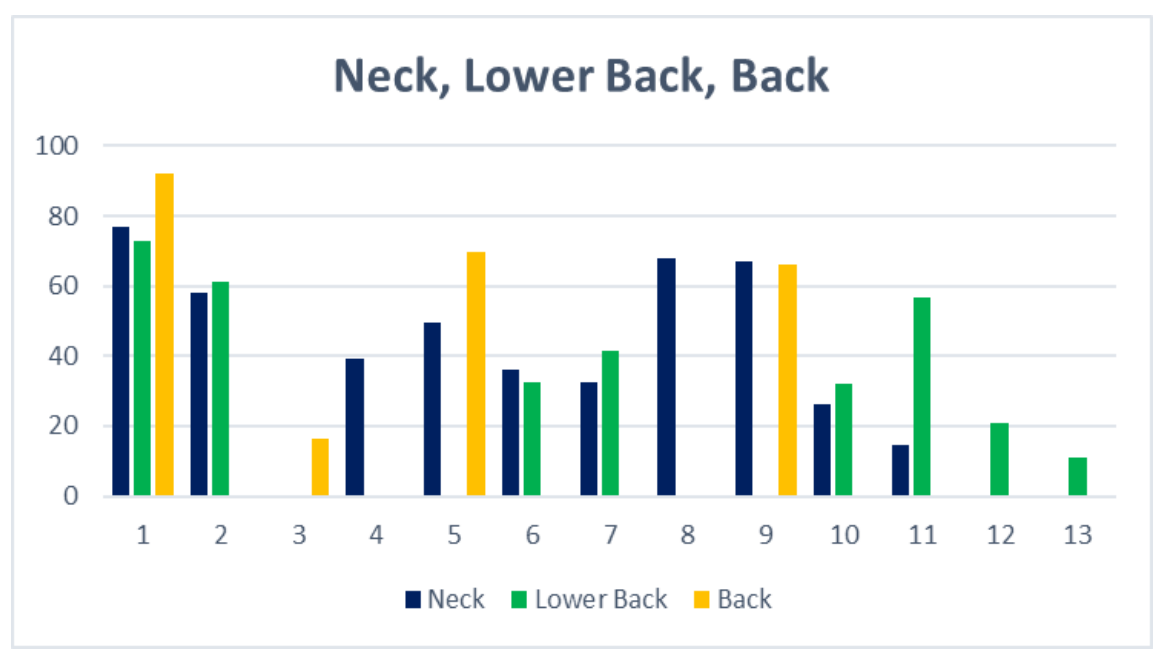

Figure 2. The three most affected body parts by WMSD.

The discrepancies between the statistics results might be attributed to the characteristics of the evaluated population and the work characteristics (Ezzatvar et al., 2020), but there is a consensus on the most affected body parts. In this sense, according to the European Agency for Safety and Health at Work, lower back pain is one of the main causes of disability and sick leave (Algarni, Alkhaldi, et al., 2020; Acaröz et al., 2019).

The severity of WMSD may increase the risk of disability, chronic pain, sick leave, reduced work capability, and early retirement (Miranda et al., 2010; Phongamwong \& Deema, 2015; Hallman et al., 2019; Troelstra et al., 2020; Vieira \& Sato, 2020).

\section{Costs}

It is estimated that an economic burden due to WMSD in Europe is approximately $2 \%$ of the Gross Domestic Product (GDP) (Bevan, 2015; Svendsen et al., 2020; Santos \& Mendes, 2020; Crawford et al., 2020).

The monetary expenses are mainly due to presenteeism and absenteeism (Nagata et al., 2018). Absenteeism can be easily calculated since it represents sick leave. However, evaluating the cost of presenteeism is more complicated because the loss of productivity is often a hidden cost. It reduces the effectiveness due to pain or disorders (Ammendolia et al., 2016), which usually offers unseen expenses.

Figure 3 reflects the economic burden (percentage) due to presenteeism and absenteeism in five developed and developing countries to illustrate the importance of reducing musculoskeletal disorder. 


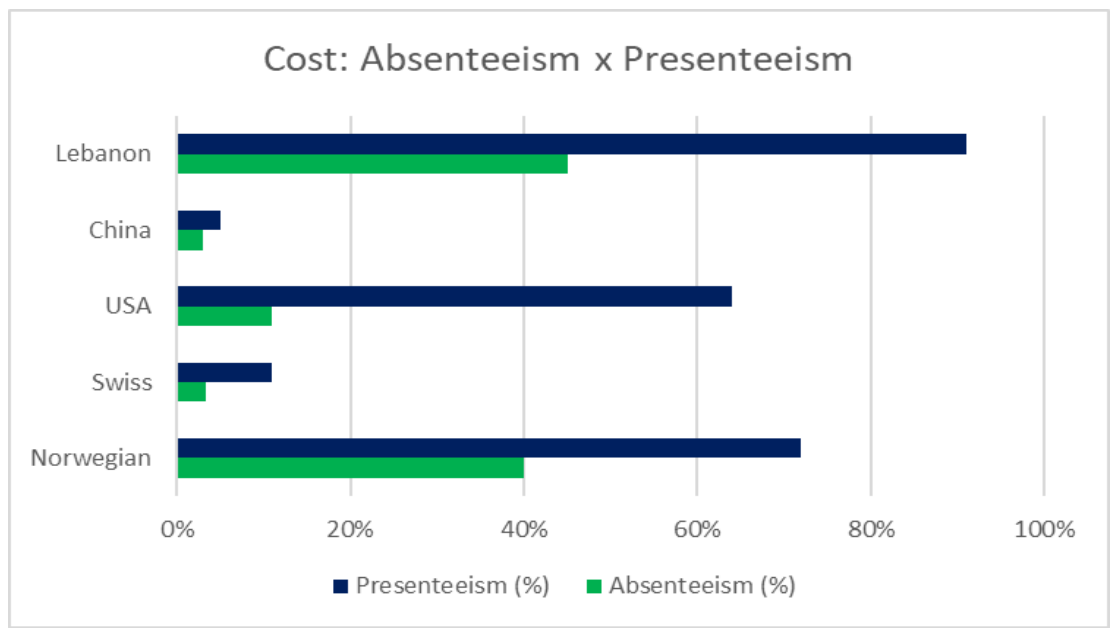

Figure 3. Comparing the total cost of absenteeism and presenteeism in five countries.

It has been assumed that presenteeism costs exceed the costs of absenteeism (van der Burg et al., 2020; Lohaus \& Habermann, 2019).

Figure 3 makes it clear that independently of developed and emergent countries, the costs due to sick leave and loss of productivity are high. It can be understood that human beings are equal concerning the body's movements and adoption of postures.

Workers not affected by WMSD symptoms have a higher quality of life (Algarni, Alkhaldi, et al., 2020), which is reflected in positive outcomes and efficiency at work and in private life. It demonstrates that improvements at work, such as awareness of adopting correct postures and reducing stressors, can minimise harmful outcomes (Acaröz et al., 2019).

\section{Causes}

Professionals from different sectors are negatively affected by overload, improper ergonomic conditions, and a lack of attention to the principles of biomechanics (Ameer \& Ashour, 2020). It can be said that the musculoskeletal system is primarily affected by repetitive work and overload, but static postures also can be damaging to physical health, increasing the risk of WMSD (Hembecker et al., 2017; Algarni et al., 2020).

It must be highlighted that extreme demanding tasks are related to psychological stress, directly associated with functional stress and illnesses (Karnaukh \& Shevtsova, 1991; Moussavi, Zare, Mahdjoub, \& Grunder, 2019).

Besides the high demand at work, sedentary behaviour and unhealthy eating habits are also detrimental to health. Regarding physical activity (PA), it has been settled that leisure PA promotes health and decreases in $20 \%$ the risk of long-term sickness absence. Contrary to leisure PA, a high occupational PA increases the risk of long-term sickness absence (Gupta et al., 2020).

Muscular injuries are caused by the insufficient restoration of energy and strength. In its turn, the first symptom of WMSD is usually muscular pain, which is directly associated with reduced work capacity, loss of productivity, and in most severe cases it can lead to absence due to illness (Jonge et al., 2019; Hallman et al., 2019; Ameer \& Ashour, 2020; Skovlund et al., 2020). Other serious consequences of WMSD are turnover intentions, depression (Frone \& Blais, 2019), and disability retirement (Pensola et al., 2016). Emphasising this sentence, in Finland, the most common reason for early retirement is musculoskeletal problems (33\%) (Söderbacka et al., 2020). These harmful results have a direct impact on workers' health and high costs. 
It must be emphasised that workers have been affected by multisite pain. The most common combination is neck and back pain (Pensola et al., 2016). Musculoskeletal disorder in several parts of the body dramatically reduces work ability (Bayattork et al., 2019; Hallman et al., 2019; Ezzatvar et al., 2020), with detrimental effects on workers and companies.

$\underline{\text { Strategies }}$

Companies have a great challenge to protect workers' health and ensure a safe workplace (Boschman et al., 2015). To improve work conditions and minimise the incidence of WMSD, occupational and hygiene professionals should implement different strategies (Nordstoga et al., 2019).

Well-planned policies can increase workers' health and reduce unnecessary costs (Crawford et al., 2020). Interventions, such as mapping the process considering individual risk factors and productivity demands, are proven efficient to achieve excellent outcomes (Atroszko et al., 2020). Training is also a low-cost and effective measure to minimise hidden productivity losses (Brunner et al., 2019), sickness- absence, and consequently prolong workers careers (Nielsen \& Midtsundstad, 2020).

Prevent harm conditions at work is crucial to avoid absenteeism and economic losses, as well as the injuries caused by the muscular response to excessive overwork (McDonald, Mulla, \& Keir, 2019). Tactics with supportive supervisors have been demonstrated to be effective to improve work conditions and reduce the risk of damaging consequences (Baral et al., 2018; Brunner et al., 2019; Söderbacka et al., 2020).

However, planning an effective strategy, risk management, and the best strategy to be taken must be evaluated according to the reality and feasibility of each organisation (Ammendolia et al., 2016; Crawford et al., 2020).

\section{CONCLUSIONS}

Work-related musculoskeletal disorders reflect a high economic burden to companies around the world, as well as prejudice worker health. The consequences to the individuals can reflect lost productivity and, in most serious cases, sickness absence.

The more significant cost is due to presenteeism, more than absenteeism, although it is difficult to evaluate its cost since it is a hidden cost. It is known that developed and underdeveloped countries have significant losses, which could be minimised with effective and inexpensive strategies.

It is important to aware workers about physical health, especially taking care of the neck and back, which are the most affected body parts. Well-designed strategies are essential to improve work conditions and should be taking according to the reality experienced.

\section{References}

Acaröz, S., Sahin, U. K., \& Akoglu, S. (2019). The investigation of work-relatedmusculoskeletal disorders among female workers in a hazelnut factory: Prevalence, working posture, work-related and psychosocial factors. International Journal ofIndustrial Ergonomics, 74. https://doi.org/10.1016/j.ergon.2019.102838

Algarni, F. S., Alkhaldi, H. A., Zafar, H., Kachanathu, S. J., Al-Shenqiti, A. M., \& Altowaijri, A. M. (2020). Self-Reported Musculoskeletal Disorders and Quality of Life in Supermarket Cashiers. International Journal of Environmental Research andPublic Health, 17(24), 1-14. https://doi.org/10.3390/ijerph17249256

Algarni, F. S., Kachanathu, S. J., \& Alabdulwahab, S. S. (2020). A Cross-Sectional Studyon the Association of Patterns and Physical Risk Factors with Musculoskeletal Disorders among Academicians in Saudi Arabia. BioMed Research International. https://doi.org/10.1155/2020/8930968

Ameer, M. A., \& Ashour, A. A. (2020). Practising physical therapy affects professionals in 
Egypt. Physiotherapy Quarterly, 28(4), 42-4 .https://doi.org/10.5114/PQ.2020.96235

Ammendolia, C., Côté, P., Cancelliere, C., Cassidy, J. D., Hartvigsen, J., Boyle, E., ... lii, B. A. (2016). Healthy and productive workers: using intervention mapping to design a workplace health promotion and wellness program to improve presenteeism. BMC Public Health, 16. https://doi.org/10.1186/s12889-016-3843-x

Atroszko, P. A., Demetrovics, Z., \& Griffiths, M. D. (2020). Work Addiction, Obsessive-Compulsive Personality Disorder, Burn-Out, and Global Burden of Disease : Implications from the ICD-11. International Journal of Environmental Research and Public Health, 17(2), 660. https://doi.org/doi.org/10.3390/ijerph17020660

Baral, S., Subedi, H. N., Paudel, P., Chand, P. B., Shrestha, M. P., McCullough, A., ... Elsey, H. (2018). Implementation research to assess a health workers performance-based management system in Nepal. Acta Paediatrica, 107(471), 24-34. https://doi.org/10.1111/apa.14406

Bayattork, M., Jakobsen, M. D., Sundstrup, E., Seidi, F., Bay, H., \& Andersen, L. L. (2019). Musculoskeletal pain in multiple body sites and work ability in the general working population: cross-sectional study among 10,000 wage earners. Scandinavian Journal of Pain, 19(1). https://doi.org/doi.org/10.1515/sjpain-2018- 0304

Bevan, S. (2015). Economic impact of musculoskeletal disorders (MSDs) on work in Europe. Best Practice \& Research Clinical Rheumatology, 29(3), 356-373. Retrieved from https://doi.org/10.1016/j.berh.2015.08.002

Boschman, J. S., Nieuwenhuijsen, K., Frings-Dresen, M. H. W., \& Sluiter, J. K. (2015). Development of hospital nurses ' work ability over a 2 year period. Occupational Medicine, 65(7), 542-548. https://doi.org/10.1093/occmed/kqv076

Brunner, B., Igic, I., Keller, A. C., \& Wieser, S. (2019). Who gains the most from improving working conditions? Health-related absenteeism and presenteeism due tostress at work. The European Journal of Health Economics, 20(8), 1165-1180. https://doi.org/10.1007/s10198-019-01084-9

Caldwell, J. A., Caldwell, J. L., Thompson, L. A., \& Lieberman, H. R. (2019). Fatigue and its management in the workplace. Neuroscience and Biobehavioral Reviews, 96(July 2018), 272-289. https://doi.org/10.1016/j.neubiorev.2018.10.024

Crawford, J. O., Berkovic, D., Erwin, J., Copsey, S. M., Davis, A., Giagloglou, E., ... Woolf, A. (2020). Best Practice \& Research Clinical Rheumatology Musculoskeletalhealth in the workplace. Best Practice \& Research Clinical Rheumatology, 34(5). https://doi.org/10.1016/j.berh.2020.101558

Ezzatvar, Y., Calatayud, J., Andersen, L. L., Vinstrup, J., Alarcón, J., \& Casaña, J. (2020). Dose-response association between multisite musculoskeletal pain and work ability in physical therapists: a cross-sectional study. International Archives of Occupational and Environmental Health, 93(7), 863-870. https://doi.org/10.1007/s00420-020-01533-6

Frone, M. R., \& Blais, A.-R. (2019). Work fatigue in a non-deployed military setting: Assessment, prevalence, predictors, and outcomes. MDPI - International Journal ofEnvironmental Research and Public Health, 16(16), 1-26. https://doi.org/10.3390/ijerph16162892

Gupta, N., Dencker-Larsen, S., Rasmussen, C. L., Mcgregor, D., Rasmussen, D. C. N., Thorsen, S. V., ... Holtermann, A. (2020). The physical activity paradox revisited :a prospective study on compositional accelerometer data and long-term sickness absence. International Journal of Behavioral Nutrition and Physical Activity, 17(1),1-9. https://doi.org/10.1186/s12966-020-00988-7

Hallman, D. M., Holtermann, A., Dencker-Larsen, S., Jørgensen, M. B., \& Rasmussen, C. D. N. (2019). Are trajectories of neck-shoulder pain associated with sick leave and work ability in workers ? A 1-year prospective study. BMJ Open, 9(3), 1-10. https://doi.org/10.1136/bmjopen-2018-022006

Hembecker, P. K., Reis, D. C., Konrath, A. C., Gontijo, L. A., \& Merino, E. A. D. (2017).Investigation of musculoskeletal symptoms in a manufacturing company in Brazil :a cross-sectional study. Brazilian Journal of Physical Therapy, 21(3), 175-183. https://doi.org/10.1016/j.bjpt.2017.03.014

Jonge, J. De, Peeters, M. C. W., \& Taris, T. W. (2019). Feeling Vital or Fatigued ? Relations with Demands and Resources in a University Context. InternationalJournal of Environmental Research and Public Health, 16(6), 124.https://doi.org/doi.org/10.3390/ijerph16162893

Karnaukh, N., \& Shevtsova, V. (1991). Thoughts on the length of the work-shift and efficient work regimens in industry. Metallurgist, 34(12), 30-31. Retrieved from https://link.springer.com/content/pdf/10.1007/BF00750115.pdf

Knoop, V., Costenoble, A., Azzopardi, R. V., Vermeiren, S., Debaina, A., Jansen, B., ...Group, G. B. S. (2019). The 
operationalization of fatigue in frailty scales: a systematic review. Ageing Research Reviews, 53. https://doi.org/10.1016/j.arr.2019.100911

Lohaus, D., \& Habermann, W. (2019). Presenteeism: A review and research directions. Human Resource Management Review, 29(1), 43-58.https://doi.org/10.1016/j.hrmr.2018.02.010

McDonald, A. C., Mulla, D. M., \& Keir, P. J. (2019). Muscular and kinematic adaptationsto fatiguing repetitive upper extremity work. Applied Ergonomics, 75, 250-256. Retrieved from https://doi.org/10.1016/j.apergo.2018.11.001

Miranda, H., Kaila-kangas, L., Heliovaara, M., Leino-Arjas, P., Haukka, E., Liira, J., \& Viikari-Juntura, E. (2010). Musculoskeletal pain at multiple sites and its effects on work ability in a general working population. Occupational \& Environmental Medicine, 67(7), 449-455. https://doi.org/10.1136/oem.2009.048249

Moussavi, S. E., Zare, M., Mahdjoub, M., \& Grunder, O. (2019). Balancing high operator's workload through a new job rotation approach : Application to an automotive assembly line. International Journal of Industrial Ergonomics, 71, 136-144. https://doi.org/10.1016/j.ergon.2019.03.003

Nagata, T., Mori, K., Ohtani, M., Nagata, M., Kajiki, S., Fujino, Y., ... Loeppke, R. (2018). Total Health-Related Costs Due to Absenteeism, Presenteeism, and Medicaland Pharmaceutical Expenses in Japanese Employers. Journal of Occupational and Environmental Medicine, 60(5), 273-280. https://doi.org/10.1097/JOM.0000000000001291

Nielsen, R. A., \& Midtsundstad, T. I. (2020). Do workplace health-promotion interventions targeting employees with poor health reduce sick-leave probability anddisability rates ? Scandinavian Journal of Public Health, 1-9. https://doi.org/10.1177/1403494820946543

Nordstoga, A. L., Vasseljen, O., Meisingset, I., Nilsen, T. I. L., \& Unsgaard-Tøndel, M. (2019). Improvement in Work Ability, Psychological Distress and Pain Sites in Relation to Low Back Pain Prognosis - A Longitudinal Observational Study in Primary Care. Spine, 44(7), E423-E429. https://doi.org/10.1097/BRS.0000000000002860

Pensola, T., Haukka, E., Kaila-kangas, L., Neupane, S., \& Leino-Arjas, P. (2016). Goodwork ability despite multisite musculoskeletal pain ? A study among occupationallyactive Finns. Scandinavian Journal of Public Health, 44(3), 300-310. https://doi.org/10.1177/1403494815617087

Phongamwong, C., \& Deema, H. (2015). The impact of multisite musculoskeletal pain on work ability among health care providers. Journal of Occupational Medicine andToxicology, 10(21), 1-5. https://doi.org/10.1186/s12995015-0063-8

Santos, M. R. dos, \& Mendes, C. (2020). Manual therapy and its role in occupational health : Reducing absenteeism and presenteeism by treating chronic pain with spinalmanipulation and mobilization in the workplace. European Journal of Integrative Medicine, 35. https://doi.org/10.1016/j.eujim.2020.101078

Silva, T. P. D. da, Araújo, W. N. de, Stival, M. M., Toledo, A. M. de, Burke, T. N., \& Carregaro, R. L. (2018). Musculoskeletal discomfort, work ability and fatigue in nursing professionals working in a hospital environment. Journal of School of Nursing - University of São Paulo, 52(e03332), 1-8. https://doi.org/doi.org/10.1590/S1980-220X2017022903332

Skovlund, S. V., Bláfoss, R., Sundstrup, E., \& Andersen, L. L. (2020). Association between physical work demands and work ability in workers with musculoskeletal pain: cross-sectional study. BMC Musculoskeletal Disorders, 21(166), 1-8. https://doi.org/doi.org/10.1186/s12891-020-03191-8

Söderbacka, T., Nyholm, L., \& Fagerström, L. (2020). Workplace interventions that support older employees' health and work ability - a scoping review. BMC Health Services Research, 20(1), 1-9. https://doi.org/10.1186/s12913020-05323-1

Svendsen, M. J., Schmidt, K. G., Holtermann, A., \& Rasmussen, C. D. N. (2020). Expert panel survey among occupational health and safety professionals in Denmark for prevention and handling of musculoskeletal disorders at workplaces. Safety Science,131. https://doi.org/10.1016/j.ssci.2020.104932

Troelstra, A. S., Straker, L., Harris, M., Brown, S., Beek, A. J. vand der, \& Coenen, P. (2020). Multimorbidity is common among young workers and related to increased work absenteeism and presenteeism: results from the population-based Raine Studycohort. Scandinavian Journal of Work, Environment and Health, 46(2), 218-227. https://doi.org/10.5271/sjweh.3858

van der Burg, L., Sepriano, A., Landewé, R., Geuskens, G., Ottenheijm, R., Dinant, G.- J., \& Boonen, A. (2020). Comparative construct validity of three presenteeism instruments in workers with musculoskeletal 
DeE

complaints: a prospective cohortstudy. RMD Open - Rheumatic \& Musculoskeletal Diseases, 6(2), 1-8. https://doi.org/10.1136/rmdopen-2020-001281

Vieira, L. M. S. M. de A., \& Sato, T. de O. (2020). Prevalence of multisite pain and association with work ability Cross-sectional study. Musculoskeletal Science andPractice, 50. https://doi.org/10.1016/j.msksp.2020.102279 